\title{
FUNDEB E CUMPRIMENTO DO PISO SALARIAL DOS PROFESSORES EM SÃO GONÇALO/RJ: UM DESAFIO À COMPLEMENTAÇÃO FACE À DIFICULDADE DO MUNICÍPIO EM ATENDER À DETERMINAÇÃO CONSTITUCIONAL
}

\author{
FUNDEB AND COMPLIANCE WITH THE TEACHERS' SALARY FLOOR IN SÃO \\ GONÇALO/RJ: A CHALLENGE TO COMPLEMENTATION FACING THE \\ MUNICIPALITY'S DIFFICULTY IN MEETING THE CONSTITUTIONAL \\ DETERMINATION
}

Fabrícia Gonçalves de Oliveira ${ }^{1}$

Cláudio Roberto Mendonça Schiphorst ${ }^{2}$

Vaneli Laurindo Chaves ${ }^{3}$

RESUMO: A lei Ir.738 de i6 de Julho de 2008 regulamentou a instituição do piso salarial para os profissionais do magistério público da educação básica. No cenário atual, os Estados e Municípios brasileiros relatam dificuldades para cumprir o novo piso salarial dos professores. Muitos governos afirmam que o cumprimento da medida dependerá de ajuda federal, já que a lei do piso estabelece que o valor mínimo deve ser pago considerando apenas o vencimento, não incluindo gratificações ou complementações, como é feito, por exemplo, em São Gonçalo/RJ. Tendo em vista a dimensão que a discussão sobre este tema vem ganhando, esta nota técnica apresenta dados que mostram a dificuldade do Município de São Gonçalo no cumprimento do Piso Salarial dos Professores, conforme determina a Constituição Federal, as tentativas do mesmo em avançar na questão, bem como os resultados de estudos que refletem a necessidade concreta e imediata de Complementação por parte do FNDE.

Palavras-Chave: Fundeb. Cumprimento do piso salarial dos professores. Desafio à complementação. São Gonçalo/RJ.

ABSTRACT: Law II.738 of July 16, 2008 regulated the institution of the minimum wage for public teaching professionals in basic education. In the current scenario, Brazilian States and Municipalities report difficulties in meeting the new salary floor for teachers. Many governments claim that compliance with the measure will depend on federal aid, as the floor law establishes that the minimum amount must

\footnotetext{
${ }^{\mathrm{I}}$ Mestre em Patologia e Ciências Clínicas pela Universidade Federal Rural do Rio de Janeiro (UFRRJ). Especialista em Agricultura Familiar Camponesa e Educação do Campo pela Universidade Federal do Ceará (UFC). Graduanda em Ciências Contábeis pela Universidade Unyleya. Analista em Gestão Pública no Município de São Gonçalo-RJ. E-mail: fgonrib@gmail.com.

${ }^{2}$ Ex-Secretário Municipal de Educação do Município de São Gonçalo/RJ.

${ }^{3}$ Ex-secretária Municipal de Educação do Município de São Gonçalo/RJ.
} 
be paid considering only the salary, not including bonuses or supplements, as is done, for exemple, in São Gonçalo/RJ. In view of the dimension that the discussion on this topic has been gaining, this technical note presents data that show the difficulty of the Municipality of São Gonçalo in complying with the Teachers' Salary Floor, as determined by the Federal Constitution, its attempts to advance the issue, as well as the results of studies that reflect the concrete and immediate need for Complementation by the FNDE.

Keywords: Fundeb. Compliance with the teachers' salary floor. challenge to complementation. São Gonçalo/RJ.

\section{INTRODUÇÃO}

A lei Ir.738 de i6 de Julho de 2008 regulamentou a alínea "e" do inciso III do caput do art. 6o do Ato das Disposições Constitucionais Transitórias, para instituir o piso salarial profissional nacional para os profissionais do magistério público da educação básica. O Piso Salarial é o valor abaixo do qual os entes federativos (União, Estados, Distrito Federal e Municípios) não poderão fixar o vencimento inicial das carreiras do magistério público da educação básica, para a jornada de, no máximo, 40 (quarenta) horas semanais.

No cenário atual, os Estados e Municípios brasileiros relatam dificuldades para cumprir o novo piso salarial dos professores em 2015. O valor passou de $\mathrm{R}_{\$}$ I.697,00 em 2014 para $R_{\$} 1.917,78$ em 2015, um reajuste de 13,01\%, acima da inflação e superior, segundo o Conselho Nacional de Secretários de Educação (Consed), à receita do Fundo de Manutenção e Desenvolvimento da Educação Básica e de Valorização dos Profissionais da Educação (Fundeb). É importante ressaltar que 2015 será um ano de ajustes fiscais, devido a uma possível retração econômica no Brasil. Portanto, um cenário com menores repasses de receitas para o Fundeb é bastante provável. Muitos governos afirmam que o cumprimento da medida dependerá de ajuda federal, já que a lei do Piso (Lei II.738/2008) estabelece que o valor mínimo deve ser pago considerando apenas o vencimento, não incluindo gratificações ou complementações, como é feito, por exemplo, em São Gonçalo/RJ.

Tendo em vista a dimensão que a discussão sobre este tema vem ganhando, esta nota técnica apresenta dados que mostram a dificuldade do Município de São 
Gonçalo no cumprimento do Piso Salarial dos Professores, conforme determina a Constituição Federal, as tentativas do mesmo em avançar na questão, bem como os resultados de estudos que refletem a necessidade concreta $e$ imediata de Complementação por parte do FNDE ( Fundeb).

\section{FUNDO NACIONAL DE DESENVOLVIMENTO DA EDUCAÇÃO BÁSICA E DE VALORIZAÇÃO DOS PROFISSIONAIS DA EDUCAÇÃO (FUNDEB)}

\section{I Conceito}

Trata-se de fundo especial, de natureza contábil (sem órgão administrativo gestor) e de âmbito estadual (isto é, que não pertence à administração da esfera estadual e não pode sofrer retenção), formado por parcela financeira de recursos federais e por recursos provenientes dos impostos e transferências dos estados, Distrito Federal e municípios, vinculados à educação por força do disposto no art. 212 da Constituição Federal. Independentemente da origem, todo o recurso gerado é redistribuído para aplicação exclusiva na educação básica. O Fundeb foi criado pela Emenda Constitucional no 53/2006 e regulamentado pela Lei no $11.494 / 2007$ e pelo Decreto no 6.253/2007, em substituição ao Fundef, que vigorou de 1998 a 2006. (Manual Orientação- Fundeb, 2013).

Com vigência estabelecida para o período 2007-2020, sua implantação teve início em Io de janeiro de 2007 , sendo plenamente concluída no terceiro ano de sua vigência, quando o total de alunos matriculados na rede pública foi considerado na distribuição dos recursos e o percentual de contribuição dos estados, Distrito Federal e municípios para a formação do Fundo atingiu o patamar de $20 \%$, calculado sobre as seguintes fontes de impostos e transferências constitucionais: Fundo de Participação dos Estados (FPE); Fundo de Participação dos Municípios (FPM); Imposto sobre Circulação de Mercadorias e sobre prestação de Serviços (ICMS); Imposto sobre Produtos Industrializados, proporcional às exportações (IPIexp); Imposto sobre Transmissão Causa Mortis e doações de quaisquer bens ou direitos (ITCMD); Imposto sobre a Propriedade de Veículos Automotores (IPVA); Imposto sobre a 
Propriedade Territorial Rural (cota-parte dos municípios) (ITRm); Recursos relativos à desoneração de exportações de que trata a LC no 87/96; Arrecadação de imposto que a União eventualmente instituir no exercício de sua competência (cotaspartes dos estados, Distrito Federal e municípios); Receita da dívida ativa tributária, juros e multas relativas aos impostos acima relacionados (Manual Orientação-Fundeb, 2013).

Além desses recursos, originários dos entes estaduais e municipais, recursos federais também integram a composição do Fundeb, a título de complementação financeira, com o objetivo de assegurar o valor mínimo nacional por aluno/ano a cada Estado, ou o Distrito Federal, em que este limite mínimo não for alcançado com os recursos dos próprios governos.

\subsection{Contextualização}

A garantia da educação básica pública - cuja responsabilidade cabe aos Estados, Distrito Federal e Municípios, com a participação suplementar da União, conforme prevê a Constituição Federal - constitui um dos grandes desafios a ser enfrentado no contexto da política de inclusão social que norteia as ações do governo federal. A criação do Fundo de Manutenção e Desenvolvimento da Educação Básica e de Valorização dos Profissionais da Educação (Fundeb) como mecanismo de ampla redistribuição de recursos vinculados à educação no país se fazia necessária para que todas as etapas e modalidades desse nível de ensino, e os entes governamentais que as oferecem à sociedade, pudessem contar com recursos financeiros com base no número de alunos matriculados, concorrendo, dessa forma, para a ampliação do atendimento e a melhoria qualitativa do ensino oferecido (Manual OrientaçãoFundeb, 2013).

Os indicadores educacionais do país revelam que muito se avançou desde 1988, quando a Constituição Federal enfatizou o dever do Estado nas garantias dos direitos do cidadão. Mas o Brasil ainda convive com enormes diferenças. Em relação à educação, as diferenças mostram-se mais evidentes entre municípios, estados e 
regiões do país e, no interior destes, entre etapas, modalidades e demais segmentos que compõem o nível básico de ensino. O Fundeb contribui para a redução das variadas formas de desigualdades educacionais existentes, estabelecendo, para a educação básica pública, equidade na distribuição dos recursos disponíveis no âmbito dos estados, Distrito Federal e municípios e maior participação federal no aporte de recursos financeiros, contribuindo para elevação do patamar de investimentos no setor (Manual Orientação-Fundeb, 2013).

Assim, o Fundeb, em vigor desde 2007, traz como objetivo dar continuidade aos pontos positivos do Fundef (Fundo de Manutenção e Desenvolvimento do Ensino Fundamental e de Valorização do Magistério), aperfeiçoando-os e ampliando o seu alcance. Além disso, tem tentado preencher as lacunas deixadas pelo antigo fundo, como a prática do baixo valor mínimo por aluno/ano, a pequena contribuição da União no montante do fundo, a competição por aluno entre os entes federados e, talvez o ponto mais negativo do Fundef: a não cobertura da educação infantil e do ensino médio, que causou o baixo investimento e desenvolvimento dessas etapas de ensino (Picanço, 2012).

\section{LEI DO PISO (LEI Ir.738/2008)}

A lei II.738/2008 instituiu o piso salarial profissional nacional para os profissionais do magistério público da educação básica, regulamentando disposição constitucional. Segundo a referida lei, o valor do Piso é aquele abaixo do qual os entes federativos não poderão fixar o vencimento inicial das carreiras do magistério público da educação básica, para a jornada de, no máximo, 40 (quarenta) horas semanais. Ela se aplica à profissionais do magistério público da educação básica: aqueles que desempenham as atividades de docência ou as de suporte pedagógico à docência no âmbito das unidades escolares de educação básica (direção ou administração, planejamento, inspeção, supervisão, orientação e coordenação educacionais) .

A lei afirma, em seu art. $2^{\circ}$, que o valor do piso salarial profissional nacional 
para os profissionais do magistério público da educação básica será de $\mathrm{R} \$ 950,00$ (novecentos e cinquenta reais) mensais, para a formação em nível médio, na modalidade Normal. Ressalta, também, que o pagamento será progressivo e proporcional. Até 31/12/2009, admite-se que para atingir o valor do piso sejam computadas as vantagens pecuniárias pagas a qualquer título e, após 31/12/2009, o valor do piso deverá corresponder ao vencimento inicial da carreira.

Até 3I de dezembro de 2009, todos os entes federados (União, Estados, o Distrito Federal e os Municípios) deverão elaborar ou adequar seus Planos de Carreira e Remuneração do Magistério tendo em vista o cumprimento do piso salarial profissional nacional para os profissionais do magistério público da educação básica.

\section{ESTUDO DO IMPACTO DA LEI DO PISO EM SÃO GONÇALO/RJ}

O Município de São Gonçalo vem frequentemente dialogando com o Sindicato dos Professores do Município (SEPE) a respeito do cumprimento da Lei do

Piso Salarial. Os reajustes concedidos nesta gestão atual totalizam 26\% (leis 489/2013, 500/2013, 576/14, e 580/2014). Em especial, no ano de 2014, houve um reajuste de 7\% em julho e de $5 \%$ em novembro. Apesar desses reajustes sucessivos, os mesmos são insuficientes para cumprimento da lei do piso, face à defasagem e falta de reajuste do salário que se deu ao longo dos últimos oito anos. Em 2014, também, aconteceu uma audiência pública de conciliação no Tribunal de Justiça do Estado do Rio de Janeiro, a qual estamos cumprindo na sua íntegra. O Município, através do decreto $\mathrm{n}^{\circ}$ 222/2014, instituiu comissão no âmbito da Secretaria Municipal de Educação, nos termos do acordo lavrado no Egrégio Tribunal de Justiça do Estado do Rio de Janeiro.

Em 2014, do valor recebido pelo Fundeb $\left(\mathrm{R}_{\$}\right.$ 140.180.631,26), segundos dados parciais da Secretaria Municipal de Controle Interno, São Gonçalo já gastou 71,74\% ( R $\$ 100.565 .584,86)$ em remuneração do magistério. Isto mostra que o Município está com despesas acima do limite mínimo de gasto (60\%) dos recursos oriundos do 
Fundeb. O saldo restante foi gasto em ações para manutenção e desenvolvimento do ensino. Vale ressaltar que parcela da Remuneração da folha de Pessoal do Município foi paga com recursos do Tesouro Municipal. Estes dados mostram que a folha de pessoal onera de forma significativa o Município.

\section{Gasto do recurso do FUNDEB \\ Parcial}

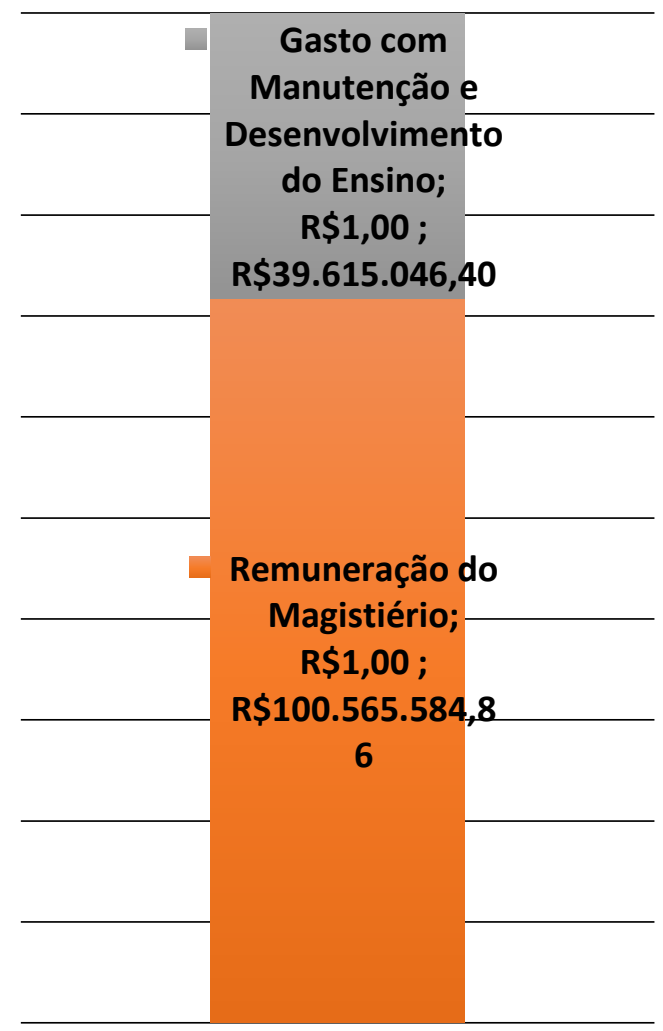

Gasto com Manutenção e Desenvolvimento do Ensino

Remuneração do Magistiério

Fonte: Secretaria Municipal de Controle Interno - Parcial

Segundo dados fornecidos pela Secretaria Municipal de Educação, por meio da Subsecretaria de Recursos Humanos, o Município gastou com folha de professores (Custo total incluindo todos os níveis de enquadramento), o equivalente a $R_{\$}$ 9.657.576,74 (Valor Bruto/mês) ( Tabela or). Portanto, se multiplicarmos por doze meses, o valor será de $\mathrm{R} \$$ II5.890.920,88 (Valor Bruto/ano). 


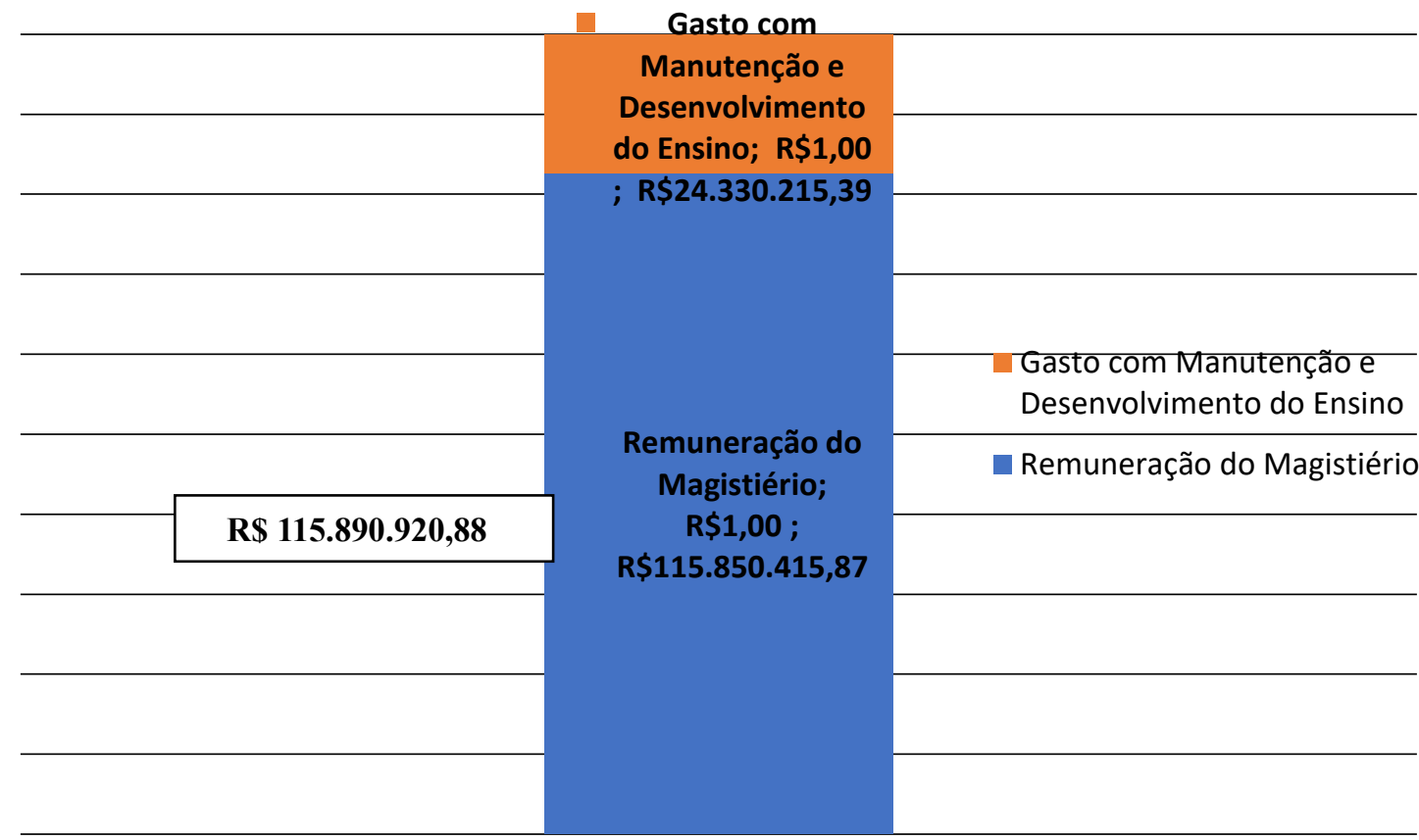

Fonte: Subsecretaria de Recursos Humanos - Dezembro

Com a incorporação do abono fornecido em novembro/2014 (5\%) (tabela 02, em anexo), o gasto com a folha de professores foi de (Custo total incluindo todos os níveis de enquadramento) $\mathrm{R} \$$ I0.018.696,93 (Valor Bruto/mês) correspondendo a um valor anual de $\mathrm{R} \$ \mathrm{I2} 20.224 \cdot 363, \mathrm{I} 6$ (Valor Bruto/ano).

Se for considerado o detalhamento da folha de professores relativo ao impacto para 2015 (13,01\% sobre o piso atual), mais o abono fornecido em novembro/2014 (5\%) (tabela 03, em anexo), o valor do gasto com a folha de professores será de (Custo total incluindo todos os níveis de enquadramento) $\mathrm{R}_{\$}$ 10.435.281,64 (Valor Bruto/mês), que corresponde a um valor anual de $\mathrm{R}_{\$}$ 125.223.379,68 (Valor Bruto/ano).

Por fim, se considerarmos o detalhamento da folha de professores relativo ao impacto do reajuste integral do piso nacional (13,01\% sobre o valor integral), (tabela 04, em anexo), o valor do gasto com a folha de professores será de (Custo total incluindo todos os níveis de enquadramento) $\mathrm{R}$ \$ 10.869.788,19 (Valor Bruto/mês), o que equivale a um valor anual de $\mathrm{R} \$$ 130.437.458,28 (Valor Bruto/ano). 

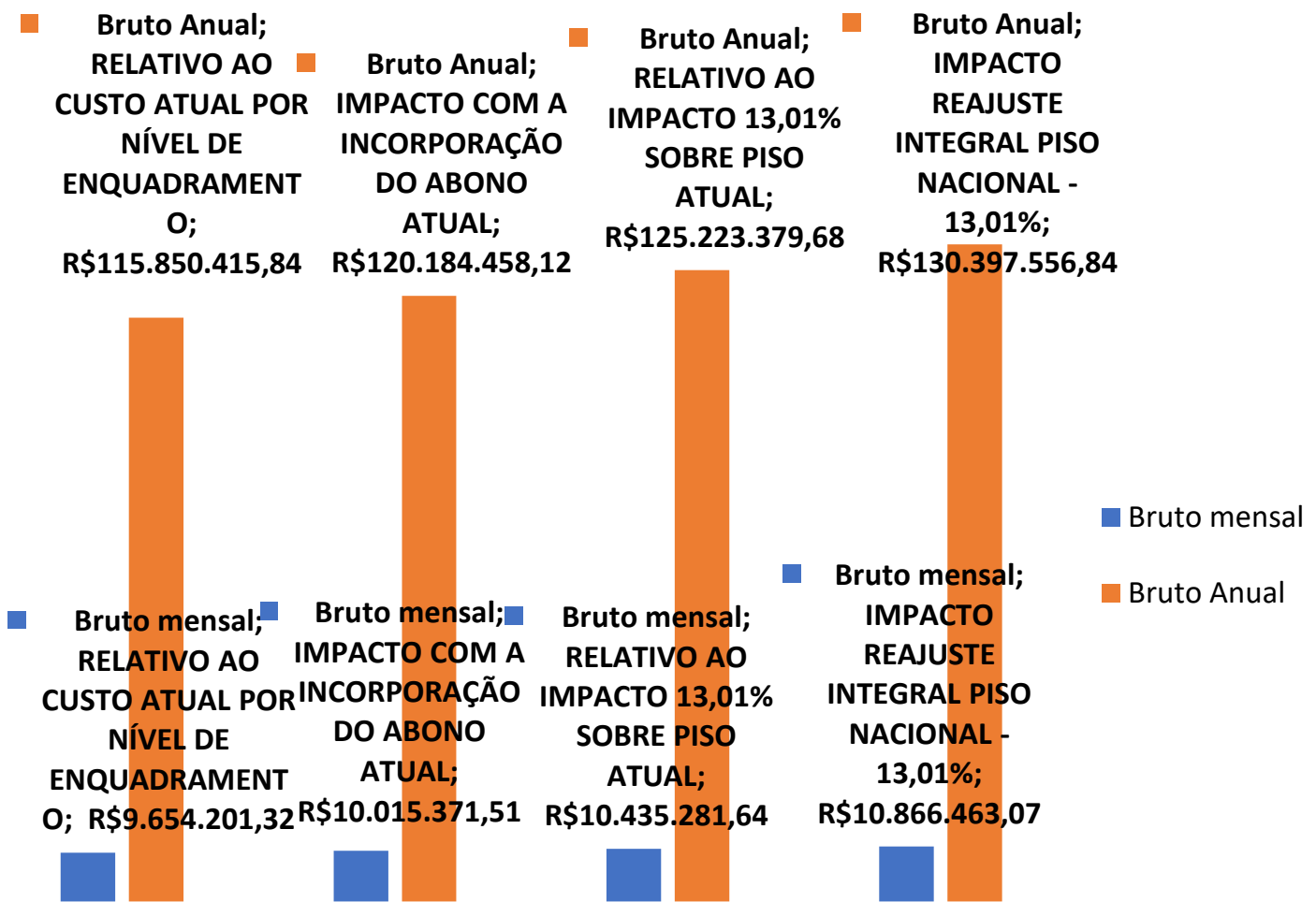

\begin{tabular}{|l|l|l|l|}
\hline R\$ 115.890.920,88 & RS 120.224. 363,16 & R\$ 130.437. 458,28 & R\$ 130.397. 458,28 \\
\hline
\end{tabular}

Fonte: Subsecretaria de Recursos Humanos

Em termos gerais, portanto, o impacto com a incorporação do piso é real e crescente. Além dos valores informados anteriormente, precisam ser incluídos os gastos realizados com encargos sociais. Somente no ano de 2014 , foi orçado $\mathrm{R} \$$ 132.000.00o,oo para gasto com folha e encargos. Deste total, uma parcela significativa, no valor de $\mathrm{R} \$ 115.850 .415,87$ foi destinada à folha de pagamento de professores. Isto representa aproximadamente $82,64 \%$ do valor repassado para a conta do Fundeb (2014). Ressalta-se que parcela da folha de pagamento de professores foi paga com recursos do Tesouro Municipal. Fazendo uma comparação entre o valor que foi orçado e o gasto com folha de professores no ano de 2014 e 2015, observa-se que para 2015 seria necessário orçar um valor de $\mathrm{R} \$$ 149.208.986,59, valor este acima da estimativa de receita para 2015 (já divulgada pelo FNDE), que será de $\mathrm{R} \$$ 
$146.635 .624,92$.

\section{Receita para 2015}

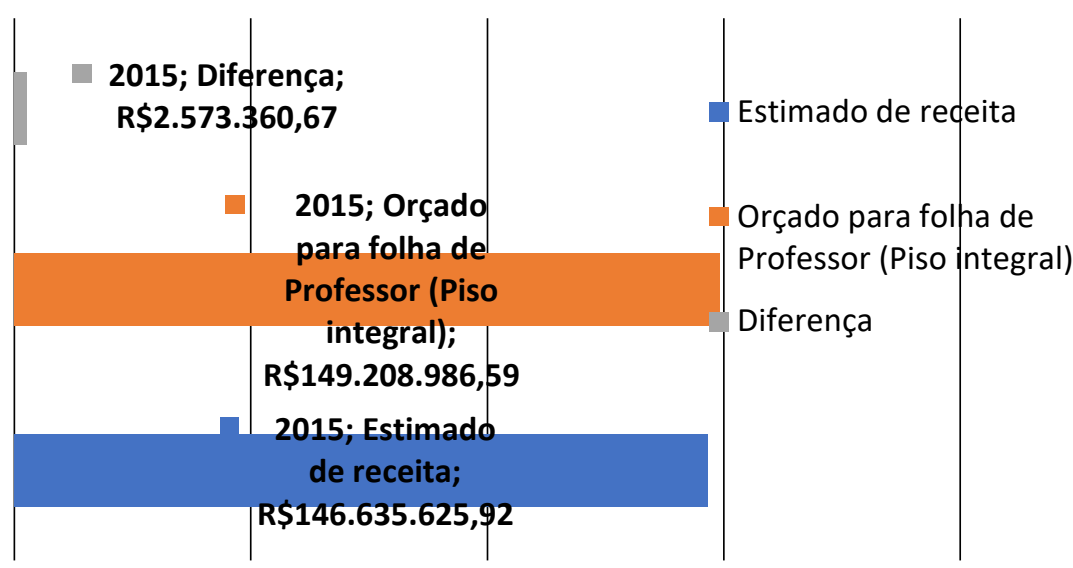

Fonte: Subsecretaria de Recursos Humanos

Deve-se levar em consideração também, na análise do cenário global, a real possibilidade de redução no repasse dos recursos. Apesar de 2015 a estimativa de receita prever o envio de $\mathrm{R} \$$ 146.635.624,92, é possível que não se receba este valor de forma integral. Isto dependerá do cenário econômico. Em 2012 foram repassado $\mathrm{R}_{\$}$ I59.148.362,46, já em 2013 foi $\mathrm{R} \$$ I42.607.380,94 e em $2014 \mathrm{R}$ 140.180.631,26. Pode-se observar que houve uma diminuição no repasse.

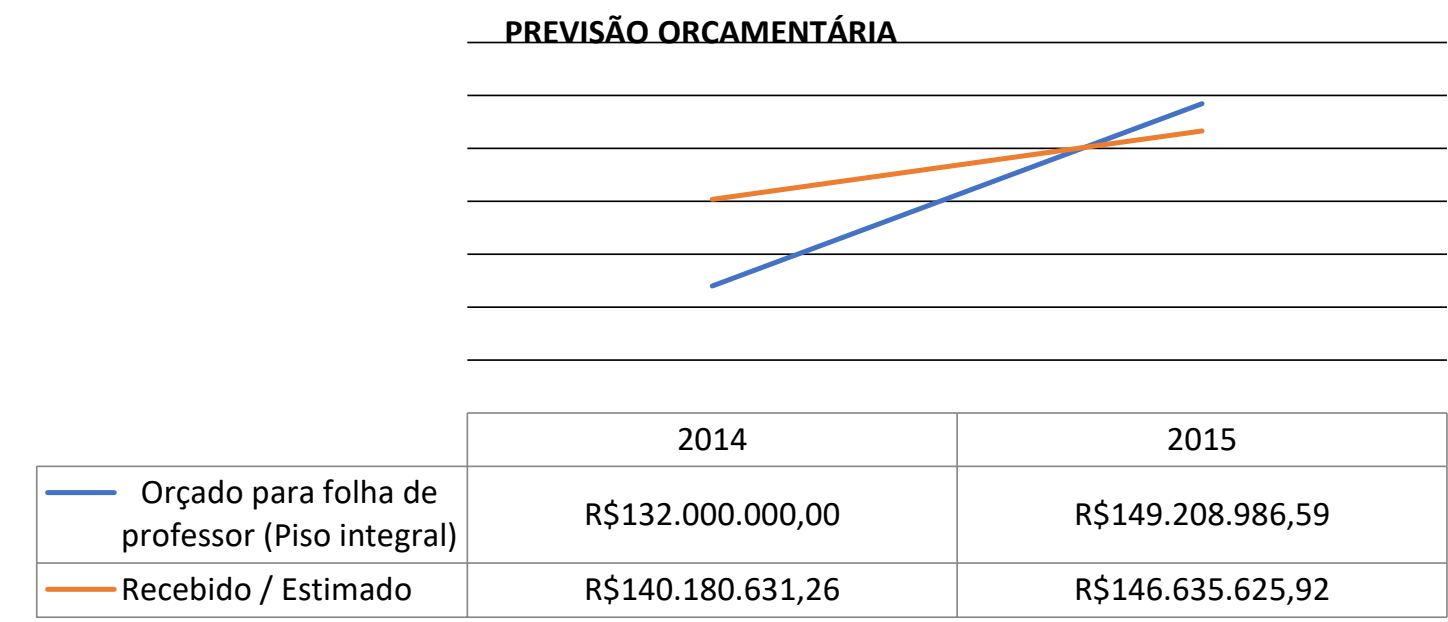

Fonte: Coordenação de Orçamento 
Fazendo uma análise dos valores repassados no mês de Janeiro pelo Fundeb (em 2013 foi de $\mathrm{R} \$ 13.367 .271$,03, já em 2014 foi $\mathrm{R} \$ 13.853 .178$,80 e em 2015 será de apenas $\mathrm{R} \$ 9.884 .243,85)$ observa-se que a redução será significativa.

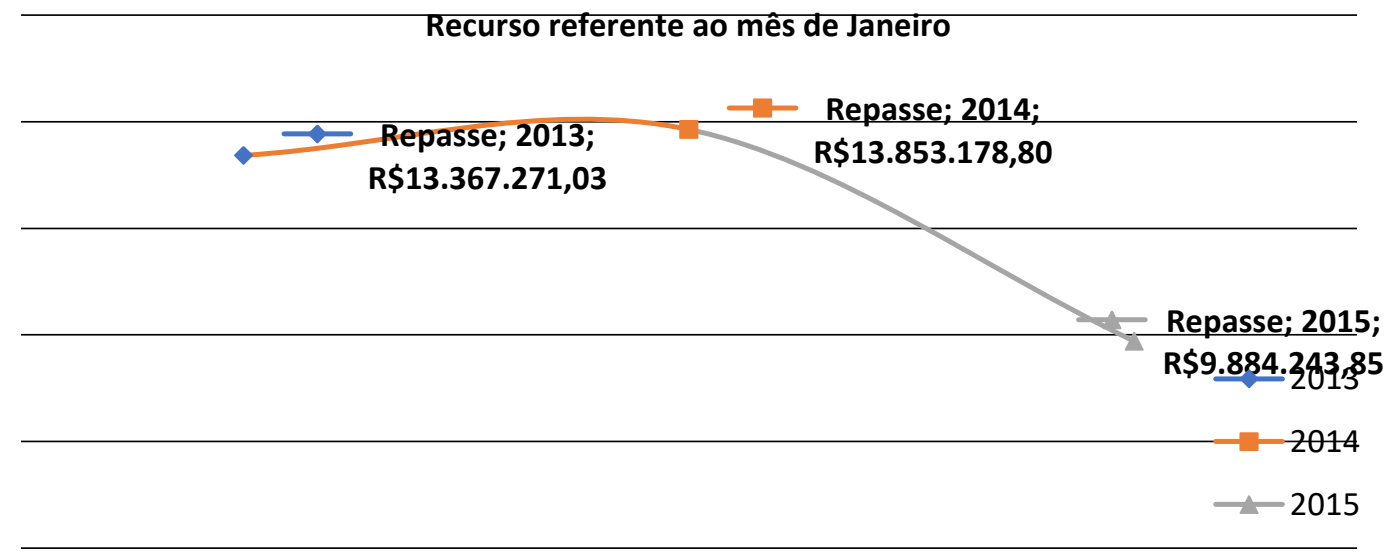

Fonte: Coordenação de Orçamento

Considerando, mediante dados expostos acima, que o impacto do reajuste salarial com o valor do piso é maior do que o previsto para arrecadar em 2015; Considerando o cenário atual de retração na economia e que o recurso que abastece o fundo vem da arrecadação de impostos; Considerando que a redução de recursos é concreta, pode-se concluir que o Município de São Gonçalo não possui condições orçamentárias e financeiras para cumprir a lei do Piso. Desta forma, para que sejam cumpridas as determinações legais, faz-se necessária a complementação dos recursos pela União, a fim de integralizar os valores referentes ao pagamento do piso salarial dos professores do Município de São Gonçalo. 


\section{ANÁlisE DAS CLÁUSULAS SOBRE A COMPLEMENTAÇÃO DA UNIÃO AO FUNDEB FACE À INCAPACIDADE DOS ESTADOS E MUNICÍPIOS}

\section{I Normas para a Complementação da União ao Fundeb}

Segundo a portaria no 213 , de 02 de Março de 201I, que aprova a Resolução no 05, de 22 de fevereiro de 20II, da comissão Intergovernamental de Financiamento para a Educação Básica de Qualidade, que em seu artigo I $^{\mathbf{O}}$ afirma que a parcela da complementação da União ao Fundeb, prevista no art. $7^{\circ}$ da lei no ${ }^{\circ}$ II.494/o7, deverá ser destinada à integralização do valor do piso salarial profissional nacional para os profissionais do magistério público da educação básica, na forma do art. $4^{\underline{0}}$ da lei no II.738/o8. A complementação na forma e no limite disposto no caput, limitar-se; a aos entes federados que demonstrem indisponibilidade orçamentária vinculada ao pagamento do Piso Salarial

Poderão apresentar pedidos os entes federados beneficiados pela complementação da União ao Fundeb, que atendam cumulativamente, aos seguintes requisitos: apliquem pelo menos $25 \%$ da receita resultante de impostos, compreendidas as transferências constitucionais, na manutenção e no desenvolvimento do ensino; preencham completamente as informações requeridas pelo Sistema de Informações sobre Orçamentos Públicos em Educação - SIOPE; cumpram o regime de gestão plena dos recursos vinculados à manutenção e ao desenvolvimento do ensino, na forma do $\S 5^{\circ}$ do art. 69 da Lei $n^{\circ}$ 9.394, de 20 de dezembro de 1996; disponham de planos de carreira para o magistério em lei específica; apresentem planilha de custos detalhada, demonstrando a necessidade e a incapacidade para o cumprimento do valor do piso e apresentem demonstração cabal do impacto do cumprimento da lei do piso nas finanças do solicitante.

\subsection{Ações em São Gonçalo/RJ}

São Gonçalo, atualmente, cumpre todos os requisitos para a Complementação dos recursos do Governo Federal ao Fundeb. No ano de 2013 foram aplicados 26,59\% 
da receita resultante de impostos, compreendidas as transferências constitucionais, na manutenção e no desenvolvimento do ensino. E no ano de 2014, 26,88\%. Foram preenchidas completamente as informações requeridas pelo Sistema de Informações sobre Orçamentos Públicos em Educação - SIOPE no ano de 2014. Cumpre, também, com o regime de gestão plena, de aplicação dos recursos vinculados à manutenção e ao desenvolvimento do ensino.

O Município dispõe de Plano de Carreira para o magistério, conforme a lei $008 / 2003$ (Lei Municipal), alterada pela lei $\mathrm{n}^{\mathrm{0}} 528 / 2013$. Regulamentou o artigo 45 da referida lei, instituindo a Comissão de Gestão do Plano de Carreira do Magistério Público Municipal, a qual foi nomeada pela Portaria Municipal oo6/2014, cuja finalidade é orientar a implantação e operacionalização do referido Plano.

Foram elaboradas, pela Subsecretaria de Recursos Humanos da Secretaria Municipal de Educação, três planilhas de custos detalhadas (em anexo), demonstrando o impacto mensal, na folha de pagamento dos professores, da incorporação do piso. A primeira demonstra o impacto com a incorporação do abono atual; a segunda é relativa ao impacto 2015 (13,01\%) sobre o piso atual; e a terceira é o impacto do reajuste integral no piso nacional. Estas planilhas subsidiaram as informações contidas nesta nota técnica e, foi a partir delas, que demonstrou-se, detalhadamente a necessidade de complementação dos recursos do Fundeb e a incapacidade real do Município de São Gonçalo em cumprir a Lei do Piso Nacional.

\section{CONSIDERAÇÕES FINAIS}

Os dados coletados pela Secretaria Municipal de Educação de São Gonçalo mostram que o tema do cumprimento da lei do Piso Nacional para os Professores de São Gonçalo tem sido abordado frequentemente nas negociações com a entidade da classe e tem acontecido avanços significativos. Mostra também a realidade do Município, o qual passou alguns anos sem reajuste no salário dos professores. Já na atual gestão, contabilizou-se $26 \%$ até o momento. Observou-se que, a gestão atual está aberta ao diálogo para cumprir tal lei, e na medida do possível, tem concedido 
reajustes. Porém, cumprir a lei do piso, de imediato, causará um impacto de dimensões elevadas ao Município, o qual, atualmente não possui aporte orçamentário e financeiro para tal fim.

Em suma, pode-se dizer que o Município de São Gonçalo não tem medido esforços para cumprir o Piso Nacional dos Professores. Porém, demonstrou-se, de forma real e detalhada, que não possui aporte orçamentário e financeiro para isso. Avançar além do planejado, comprometerá o seu orçamento, e consequentemente, os compromissos firmados por este Município.

É importante considerar que temos cumprido os requisitos solicitados pela portaria 213/20II (FNDE) para a complementação da União ao Fundeb, conforme descrito abaixo: aplicou-se $26,59 \%$ da receita resultante de impostos, compreendidas as transferências constitucionais, na manutenção e no desenvolvimento do ensino, no ano de 2014; Foram preenchidas completamente as informações requeridas pelo Sistema de Informações sobre Orçamentos Públicos em Educação - SIOPE no ano de 2014; O Município cumpre, também, com o regime de gestão plena, de aplicação dos recursos vinculados à manutenção e ao desenvolvimento do ensino; $O$ mesmo dispõe de Plano de Carreira para o magistério, conforme a lei oo8/2003 ( Lei Municipal), alterada pela lei 528/2013; Está apresentada, em anexo, a planilha de custo detalhada, demonstrando a real necessidade e a impossibilidade para cumprimento do valor do piso; Está apresentada, em anexo, também, a demonstração cabal do impacto da lei ${ }^{\circ}$ II.738/2008. Há de se ressaltar, também, que não está contemplada nesta planilha a carência atual de professores, sendo esta de aproximadamente 314 ( 245 Docente II e 69 Docente I). Este dado trará um impacto ainda maior na folha de pagamento. Diante do exposto, tendo em vista a dificuldade em cumprir o novo piso integral nacional do magistério, o Município busca novos aportes de recursos por parte deste ente federado para cumprir tal meta. 


\section{ANEXOS}

Tabela I: CUSTO ATUAL POR NÍVEL DE ENQUADRAMENTO

\begin{tabular}{|c|c|c|c|c|c|}
\hline \multicolumn{6}{|c|}{$\begin{array}{l}\text { DETALHAMENTO FOLHA DE PROFESSORES } \\
\text { RELATIVO AO CUSTO ATUAL POR NÍVEL DE ENQUADRAMENTO }\end{array}$} \\
\hline \multirow{2}{*}{$\begin{array}{c}\text { Referência } \\
11 \\
\end{array}$} & \multicolumn{2}{|c|}{ Valor } & \multirow{2}{*}{$\begin{array}{c}\text { Quantitativo } \\
449 \\
\end{array}$} & \multicolumn{2}{|c|}{$\begin{array}{l}\text { Total Bruto } \\
\text { Por Referência }\end{array}$} \\
\hline & $\mathbf{R} \boldsymbol{\$}$ & 875,33 & & $\mathrm{R} \$$ & $571.571,06$ \\
\hline 12 & $\mathrm{R} \$$ & $1.006,63$ & 52 & $\mathrm{R} \$$ & $72.769,34$ \\
\hline 13 & $\mathbf{R} \mathbf{S}$ & $1.157,62$ & 316 & $\mathrm{RS}$ & $505.196,53$ \\
\hline 14 & $\mathrm{R} \$$ & $1.331,27$ & 392 & $\mathrm{R} \$$ & $732.093,77$ \\
\hline 15 & $\mathrm{R} \$$ & $1.530,96$ & 459 & $\mathrm{R} \$$ & $1.038 .455,49$ \\
\hline 16 & $\mathrm{R} \$$ & $1.760,60$ & 621 & $\mathrm{R} \$$ & $1.695 .550,66$ \\
\hline 17 & $\mathrm{R} \$$ & $2.024,69$ & 598 & $\mathrm{RS}$ & $1.927 .048,46$ \\
\hline 18 & $\mathrm{RS}$ & $2.328,40$ & 462 & $\mathrm{R} \$$ & $1.734 .996,10$ \\
\hline 19 & $\mathrm{R} \$$ & $2.677,65$ & 186 & $\mathrm{R} \$$ & $902.043,22$ \\
\hline 20 & $\mathrm{RS}$ & $3.079,30$ & 73 & $\mathrm{RS}$ & $457.177,60$ \\
\hline 21 & $\mathrm{R} \$$ & $3.541,20$ & 1 & $\mathrm{R} \$$ & $5.896,03$ \\
\hline 22 & $\mathrm{R} \$$ & $4.072,38$ & 2 & $\mathrm{RS}$ & $14.728,48$ \\
\hline \multicolumn{3}{|c|}{ TOTAIS: } & 3.611 & $\mathrm{R} \$$ & $5.526,74$ \\
\hline
\end{tabular}

\section{OBSERVAÇÕES}

${ }^{1}$ Considerando no cálculo, além do salário base, todas as demais vantagens percebidas pelo servidor, de acordo com informações da folha de dezembro/14.

* Valor do Abono pago aos professores Doc. II na referência 11 para alcançar o piso nacional: $\mathrm{R} \$ \mathbf{5 8 , 0 2}$ PISO DO DOC. II INICIA NA REFERÊNCIA 11

PISO DOC. I INICIA NA REFERÊNCIA 13 
Tabela 2: INCORPORAÇÃO DO ABONO ATUAL

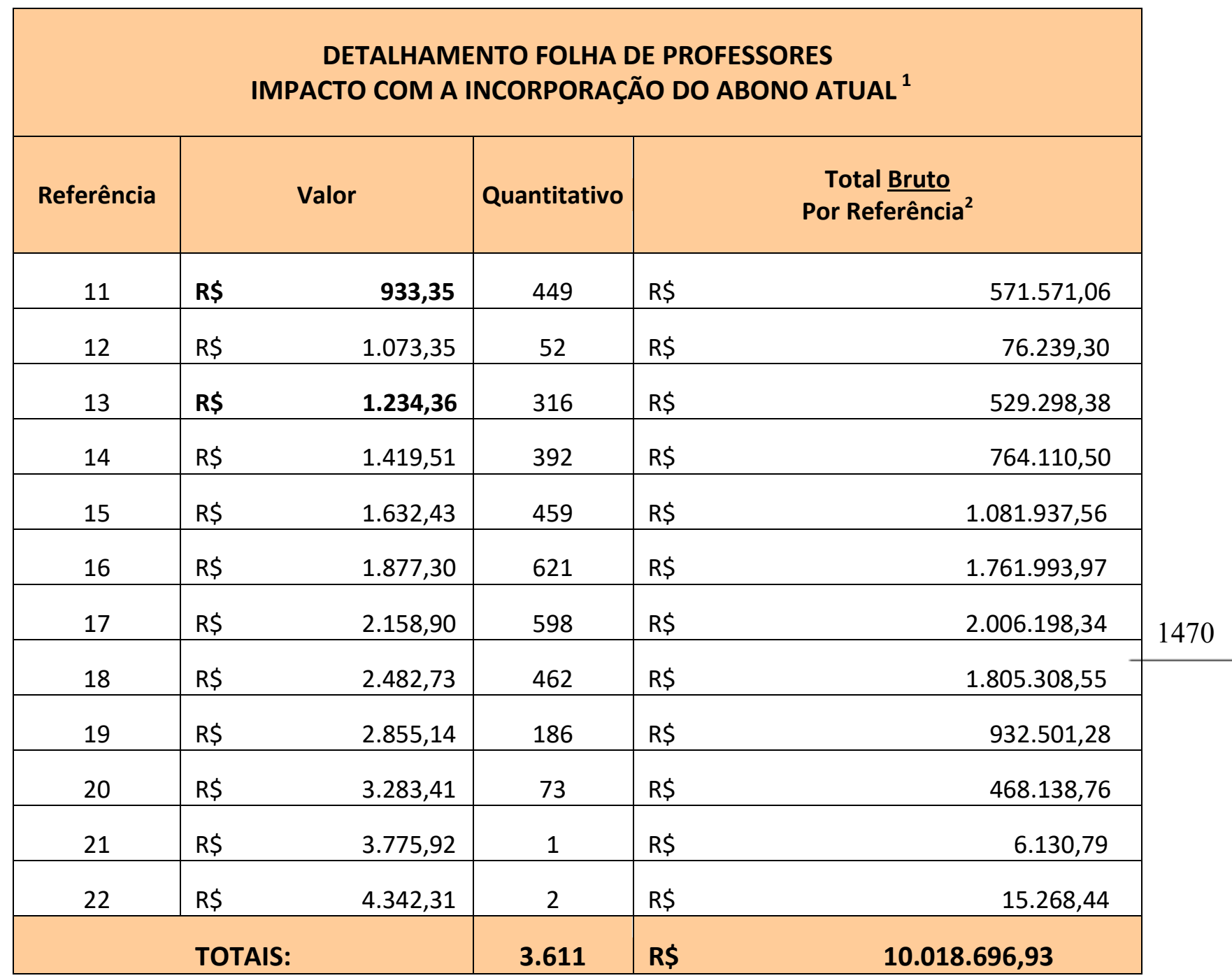

\section{OBSERVAÇÕES}

${ }^{1}$ ABONO ATUAL DE R\$ 58,02

${ }^{2}$ Considerando no cálculo, além do salário base, todas as demais vantagens percebidas pelo servidor, de acordo com informações da folha de dezembro/14.

PISO DO DOC. II INICIA NA REFERÊNCIA 11

PISO DOC. I INICIA NA REFERÊNCIA 13 
Tabela 3: INCORPORAÇÃO DE 13\% SOBRE O PISO ATUAL MAIS ABONO

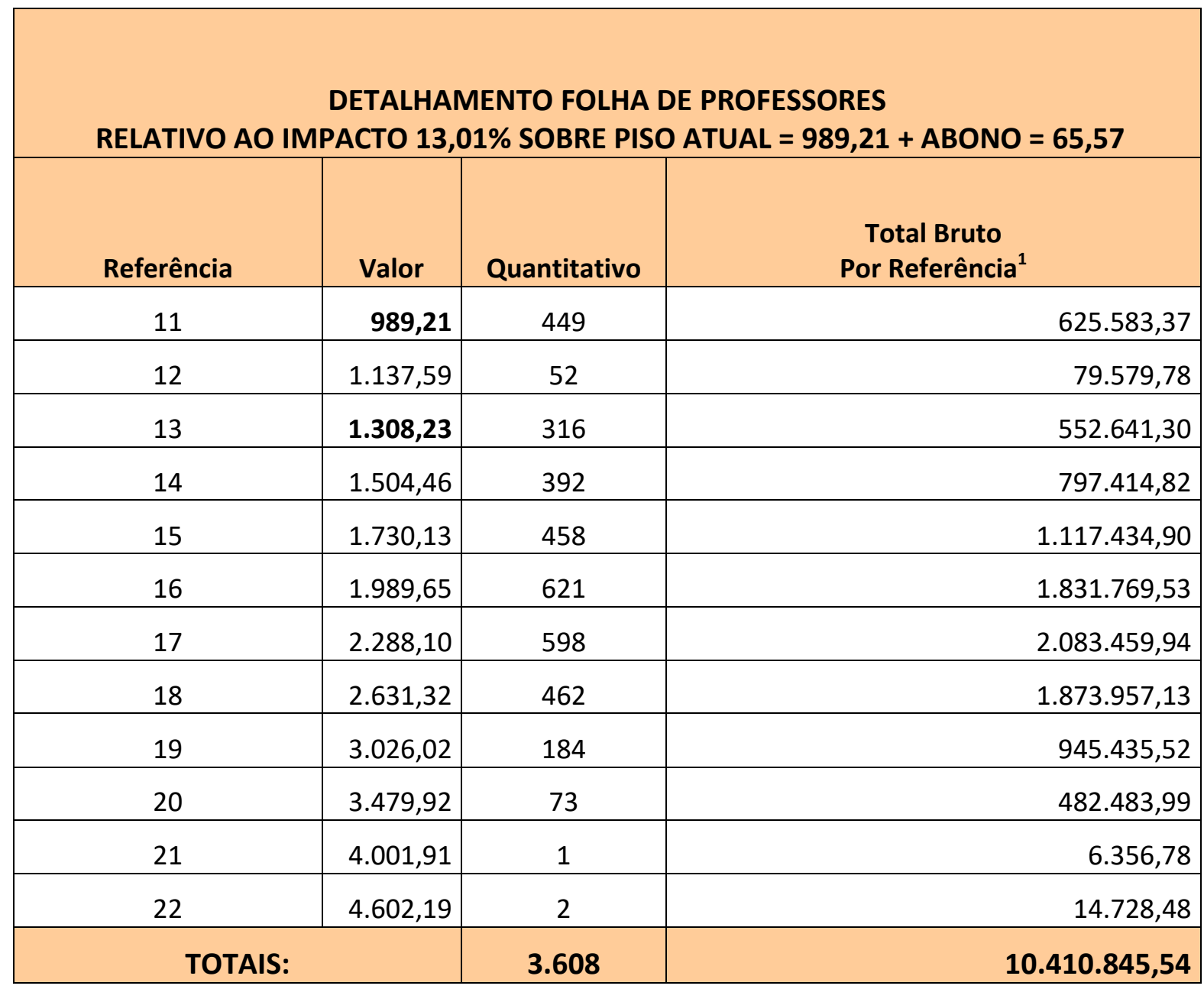

\section{OBSERVAÇÕES}

${ }^{1}$ Considerando no cálculo, além do salário base, todas as demais vantagens percebidas pelo servidor, de acordo com informações da folha de dezembro/14.

PISO DO DOC. II INICIA NA REFERÊNCIA 11

PISO DOC. I INICIA NA REFERÊNCIA 13

Constam na folha três professores nomeados ao cargo de Subsecretario e que não foram incluidos no detalhamento, por não constar informações de nível de enquadramento e salário base do respectivo cargo.

A soma total do custo mensal líquido destes é de $R \$ 19.196,18$. 


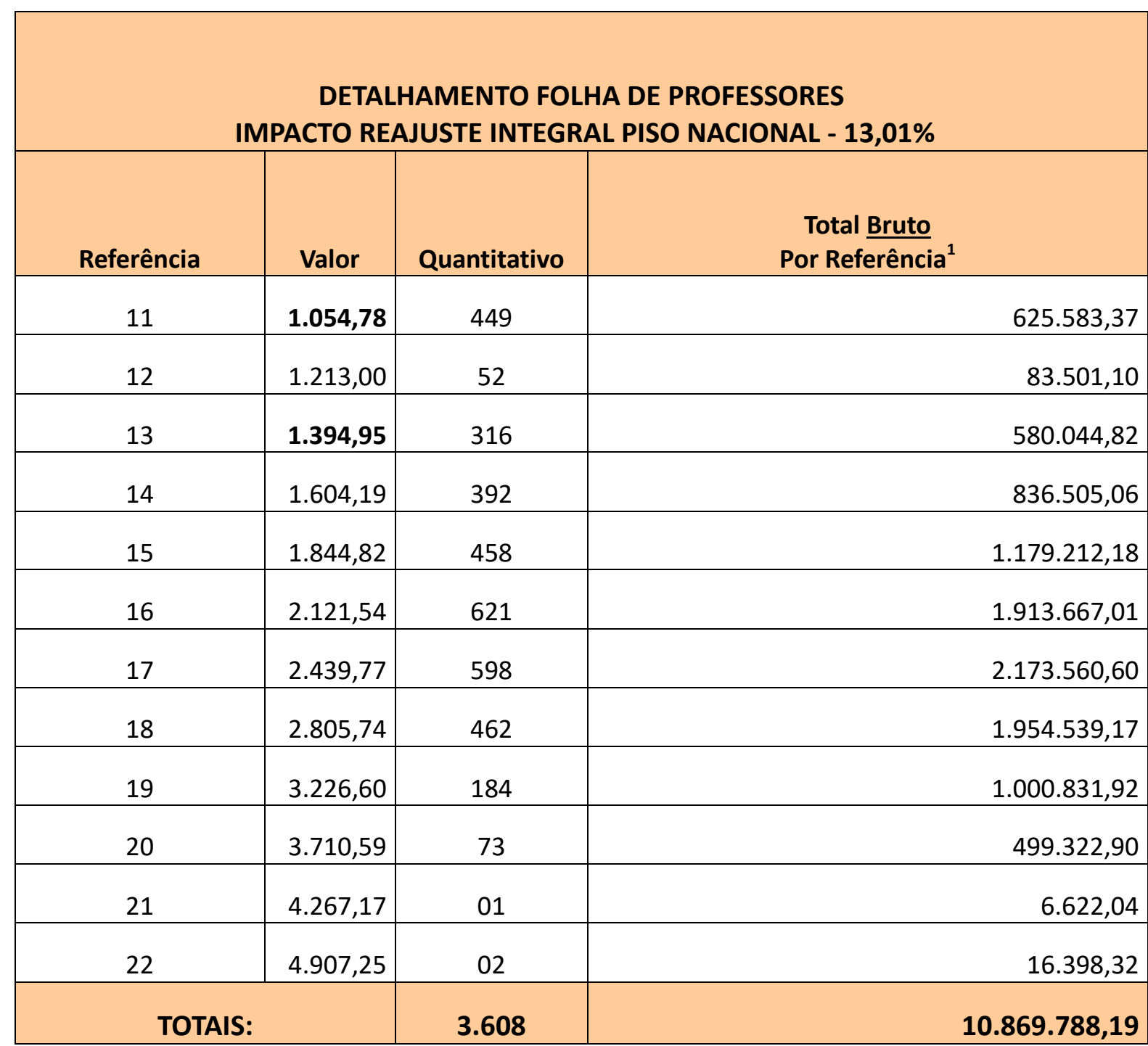

\section{OBSERVAÇÕES}

${ }^{1}$ Considerando no cálculo, além do salário base, todas as demais vantagens percebidas pelo servidor, de acordo com informações da folha de dezembro/14.

PISO DO DOC. II INICIA NA REFERÊNCIA 11

PISO DOC. I INICIA NA REFERÊNCIA 13 


\section{REFERÊNCIAS BIBLIOGRÁFICAS}

I. www.fnde.gov.br/.../196-manuais?...manual-de-orientacao-do-fundeb.2013

2. http://www.planalto.gov.br/ccivil_03/_ato2007-2010/2008/lei/li.738.htm 3. http://www.planalto.gov.br/ccivil_03/constituicao/Emendas/Emc/e mc53.htm

4. http://www.planalto.gov.br/ccivil_03/_ato20072010/2007/lei/li.494.htm

5. http://www.planalto.gov.br/ccivil_03/_ato20072010/2007/Decreto/D6253.htm

6. Picanço, Bruno Cordovil, 19. A regulação do Estado na Educação Básica por meio da política d efundos/Bruno Cordovil Picanço-2orz.

7. www.fnde.gov.br/fnde/legislacao/portarias/item/3591-portaria-mecno-213-de-o2-de-março-de-20II

8. Secretaria Municipal de Educação. Subsecretaria de Recursos Humanos. Assessoria Jurídica.

9. Prefeitura Municipal de São Gonçalo. Secretaria Municipal de Controle Interno. 